\title{
Comparação entre o crescimento de Xanthomonas Campestris (Pammel) Linhagens Mutantes resistentes a Antibióticos e Linhagens não Mutantes de Fammel Dowson ${ }^{(1)}$
}

J. LUCIO DE AZEVEDO e RAHME NELLY NEDER*

Escola Superior de Agricultura «Luiz de Queiroz»

(1) Recebido para publicação em 23 de setembro de 1963.

(*) Instituto Zimotécnico - Piracicaba. 


\section{INTRODUÇÃO}

Um dos tipos de mutação mais bem estudados em Genética de Bactérias, diz respeito a mutantes resistentes a agentes inibidores, incluindo ai os antibióticos. Mutantes resistentes aos mais diversos antibióticos tem sido encontrados em pràticamente tôdas as espécies bacterianas estudadas como provam as revisões de BRYSON e SZYBALSKY em 1955 e SCHNITZER e GRUNBERG em 1957. Tais mutantes, muitas vêzes têm uma taxa de crescimento igual ao do não mutante e, outras vêzes essa taxa tem sido mais baixa. Assim é que, QUADLING em 1960, não verificou diferenças entre o crescimento de Xanthomonas phaseoli sensivel, comparado com um mutante dessa bactéria resistente à estreptomicina; no entanto, comparando a linhagem original da bactéria em questão, com mutantes dependentes de estreptomicina, verificou que a taxa de crescimento dos mutantes dependentes era a metade da encontrada para a linhagem original.

A finalidade do presente trabalho, foi então, a de comparar as curvas de crescimento de uma linhagem de Xanthomonas campestris com as curvas de crescimento de três mutantes dessa bactéria resistentes à estreptomicina, penicilina e aureomicina, respectivamente. Estudos foram também realizados com misturas de células mutantes e não mutantes com o intuito de verificar se o crescimento da mistura sofria uma variação comparado com o crescimento da linhagem não mutante da referida bactéria.

\section{MATERIAL E MÉTODOS}

Em nosso trabalho foi utilizada uma linhagem da bactéria Xanthomonas campestris (Pammel) Dowson e três mutantes dessa bactéria resistentes respectivamente à $8000 \mathrm{mcg} / \mathrm{ml}$ de streptomicina, $100 \mathrm{mcg} / \mathrm{ml}$ de penicilina e $1 \mathrm{mcg} / \mathrm{ml}$ de aureomicina. Tanto a linhagem sensivel como ns mutantes resistentes foram obtidos em trabalho anterior AZEVEDO (1961) e AZEVEDO (1963).

O meio sólido utilizado foi o Nutriente ágar da Difco. O meio líquido utilizado foi o liquido nutriente também da Difco. Os antibióticos utilizados foram o sulfato de dihidroestreptomicina da Merck Sharp Dohme S. A., a Penicilina G potássica cristalina da Fontoura Wyeth S. A. e o cloridrato de clotetracilina cristalina da Cyanamid Química do Brasil S. A. divisão Lederle. Para maior facilidade tais antibióticos são designados no presente trabalho por Estreptomicina, Penicilina e Aureomicina respectivamente. As soluções de antibióticos foram preparados momentos 
antes de serem usadas, por dissolução de quantidades apropriadas, em água destilada.

Para medir quantitativamente o crescimento bacteriano, empregou-se o método da contagem de células feito indiretamente através da contagem de colônias em placas conforme citam Pelezar e Reid em 1958. Culturas de uma semana da linhagem original e mutantes resistentes, eram diluidas de modo que 10 a 300 células fossem inoculadas em tubos com $10 \mathrm{ml}$ de líquido nutriente. Foram assim inoculadas as seguintes séries de tubos (6 tubos para cada série).

linha original

mut. resist. estreptomicina

mut. resist. penicilina

mut. resist, aureomicina

mut. resist. estreptomicina

mut. resist. penicilina

mut, resist, aureomicina

linhagem orig. + mut. resist. estrep.

linhagem orig. + mut. resist. penic.

linhagem orig. + mut. resist. aureo. líquido nutriente

lícuido nutriente

líquido nutriente

liquido nutriente

líquido nutriente $+12 \mathrm{mcg} / \mathrm{ml}$ estrept.

líquido nutriente $+50 \mathrm{mcg} / \mathrm{ml}$ penicilina

liquido nutrientee $+0,2 \mathrm{mcg} / \mathrm{ml}$ aureomicina

liquido nutriente $+0,2 \mathrm{mcg} / \mathrm{ml}$ aureomicina

liquido nutriente

liquido nutriente

líquido nutriente.

Amostras foram retiradas nas horas $0 ; 3 ; 24 ; 48 ; 72 ; 96$ e, semeadas em placas com nutrientes ágar. As placas foram incubadas a $28^{\circ} \mathrm{C}$ e, depois de 3 dias foram contadas as colônias. Para cada tratamento foram feitas três repetições.

Para a determinação do número de bactérias sensiveis e resistentes nos tratamentos que continham misturas de mutantes e não mutantes, empregou-se a técnica da réplica, de LEDERBERG e LEDERBERG (1952). Placas contendo 30 a 100 colônias foram utilizadas. Na mistura de células sensíveis + resistentes à estreptomicina, foram feitas réplicas para placas com nutriente-ágar + $+20 \mathrm{mcg} / \mathrm{ml}$ de estreptomicina. Na mistura de sensiveis + resistentes à penicilina, as réplicas foram feitas para placas com nutrientes ágar $+5 \mathrm{mcg} / \mathrm{ml}$ de penicilina e, finalmente, as réplicas na mistura de sensiveis + resistentes à aureomicina, foram feitas para placas com nutrientes ágar $+0,5 \mathrm{mcg} / \mathrm{ml}$ de aureomicina. Quando as placas continham um número muito pequeno, ou, um número exagerado de colônias, fizeram-se repicagens de colônias para placas com as quantidades de antibióticos já citadas. Sem- 
pre foi feito o controle, em placas com nutrientes ágar sem antibiótico. Puderam assim ser estabelecidas as porcentagens de células resistentes e sensíveis, nas misturas, nos diversos tempos ensaiados

\section{RESULTADOS}

O quadro I, dá o número de bactérias encontradas, nos diversos tempos ensaiados, para as dez séries. Os gráficos I, II e III representam as curvas de crescimento da linhagem original comparadas com a dos mutantes resistentes em meio com e sem antibiótico e ainda dão as curvas das misturas de células sensiveis e resistentes.

O quadro Il representa o número de gerações e o tempo de geração de tôdas as culturas ensaiadas tomando-se como referência para comparação, o incremento do número de bactérias entre 24 e 48 horas.

O quadro III dá as porcentagens de bactérias resistentes achadas, nos diversos tempos ensaiados, numa mistura de células sensíveis e resistentes à estreptomicina. O quadro IV dá a porcentagem de células resistentes encontradas, em mistura de bactérias sensiveis e resistentes à penicilina. O quadro $V$ dá as porcentagens de bactérias resistentes encontrados em mistura de células sensiveis e resistentes à aureomicina.

\section{DISCUSSÃO E CONCLUSÕES}

Pela observação dos quadros I e II e dos çráficos I. II e III, podemos verificar que o crescimento da linhagem original, pouco difere do crescimento do mutante resistente à estreptomicina, tanto em neio com antibiótico cono $\mathrm{cm}$ meio sem antibiótico. A mistura da linhagem original sensivel e do mutante resistente a estrepto. micina apresenta uma curva de crescimento igual ao das duas linhagens separadas. O crescimento da linhagem original também não difere do crescimento do mutante resistente à penicilina em meio sem antibiótico. $O$ crescimento do mutante resistente à penicilina em meio com $50 \mathrm{mcg} / \mathrm{ml}$ de antibiótico foi bem mais lento, comparado com o seu crescimento em meio sem antibiótico. Provàvelmente, o que houve aí foi uma reversão de células resistentes para sensiveis com consequente morte dessas células revertidas. Colônias resistentes para penicilina, provindas dêsse ensaio, foram isoladas e o seu crescimento novamente ensaiado. Os resultados foram os mesmos já encontrados anteriormente provando que o 
mutante estava em estado puro e, não, misturado com células sensiveis iniciais. O mutante resistente à aureomicina apresenta um crescimento mais lento do que a linhagem original, tanto em meio com antibiótico como em meio sem o antibiótico em questão.

As taxas de crescimento representadas no quadro II, pelo tempo de geração das diversas linhagens ensaiadas, referem-se ao período de tempo entre 24 e 48 horas. São apenas dados aproximados, tomando-se sòmente 2 pontos da curva como referência, pois a nossa finalidade ai foi a de estabelecer apenas um têrmo de comparação entre o crescimento das diversas linhagens.

Pela observação dos quadros III e IV, podemos verificar que não houve uma variação significativa entre o número de bactérias sensíveis e resistentes nas misturas, nos diversos tempos ensaiados; as porcentagens encontradas não diferiram estatisticamente das porcentagens iniciais. Isso significa que o crescimento da linhagem sensivel não prejudicou o crescimento do mutante ou viceversa. No caso do mutante resistente à aureomicina (quadro V), sendo seu crescimento. mais lento que o da linhagem original, houve uma variação significativa em dois dos três experimentos feitos. $\mathrm{O}$ aumento das células sensíveis com o tempo, não foi no entanto proporcional, talvez devido ao fato de que a aureomicina, com o tempo, perde gradativamente sua ação, em meio sólido, o que acarretaria variaçỗes nas contagens.

\section{RESUMO}

Foi comparado o crescimento de uma linhagem de Xanthomonas campestris (Pammel) Dowson, com o crescimento de 3 linhagens dessa bactéria resistente à estreptomicina, penicilina e aureomicina. O crescimento da linhagem original, não diferiu do crescimento dos mutantes resistentes à estreptomicina e penicilina. $O$ crescimento do mutante resistente à aureomicina foi mais lento do que o da linhagem original. O mutante resistente à estreptomicina apresentou o mesmo indice de crescimento, tanto em meio sem antibiótico, como em meio suplementado com a droga, o mesmo acontecendo com o mutante resistente à aureomicina. O mutante resistente à penicilina teve crescimento reduzido em meio suplementado com a droga em questão. Misturas de células sensíveis e resistentes à estreptomicina mantiveram-se constantes quanto à porcentagem de células sensíveis e resistentes inicialmente inoculadas, o mesmo acontecendo com a mistura de bactérias sensíveis e resistentes à penicilina. Houve uma variaçāo nessas porcentagens, para o caso da aureomicina. 


\section{SUMMARY}

The present paper deals with the study of the growth of Xanthomonas campestris (Pammel) Dowson sensitive to streptomycin, penicillin and aureomycin compared with the growth of three resistant mutants to these drugs.

The original strain sensitive, presented the same growth rate than the resitant strains to streptomycin and penicillin but, grew better than the resistant strain to aureomycin.

The resistant mutants to streptomycin and aureomycin presented the same growth rate in liquid medium plus antibiotic and in liquid medium without antibiotic.

The resistant strain to penicillin grew better in medium without this antibiotic.

The ratio between sensitive cetls and resistant cells were studied when a mixture of cells were made.

\section{BIBLIOGRAFIA}

AZEVEDO, J. L. JE - 1961 - Resistência e mutação de Xanthomonas campestris (Pemml) jowson, em relaçâo a alguns antibióticos. Tese (le Doutoramento aprescntada à E.S.A. «I uiz de Queiroz» - Piracicaba. Brasil.

AZEVEDO, J. L. JE - 1963 - Mutantes resistentes a antibióticos cm Xanthomonas campestris (Pammel) Dowson. - No prélo.

BRYSON, V. e SZYBALSKY, W. - 1955 - Microbial drug resistance. Advanc. Genctic, 7: 1-47.

LEDERBERG, J. e LEDERBERG, E. M. - 1952 - Replica plating and selection of bacterial mutants. J. Bact. 63: 399-406.

PELCZAR, M. J. Jr. e REID, R. D. - 1958 - Microbiology McGraw-MHill Book Co. Inc., New York.

QUADLING, C. - 1960 - Mutation confering streptomycin resistance in Xanthomonas phaseoli. Can. J. Microbiol. 6: 387-396.

SCHNITZER, R. J. e GRUMBERG, E. - 1957 - Drug resistance of microrganisms. Academic Press Inc., New York. 


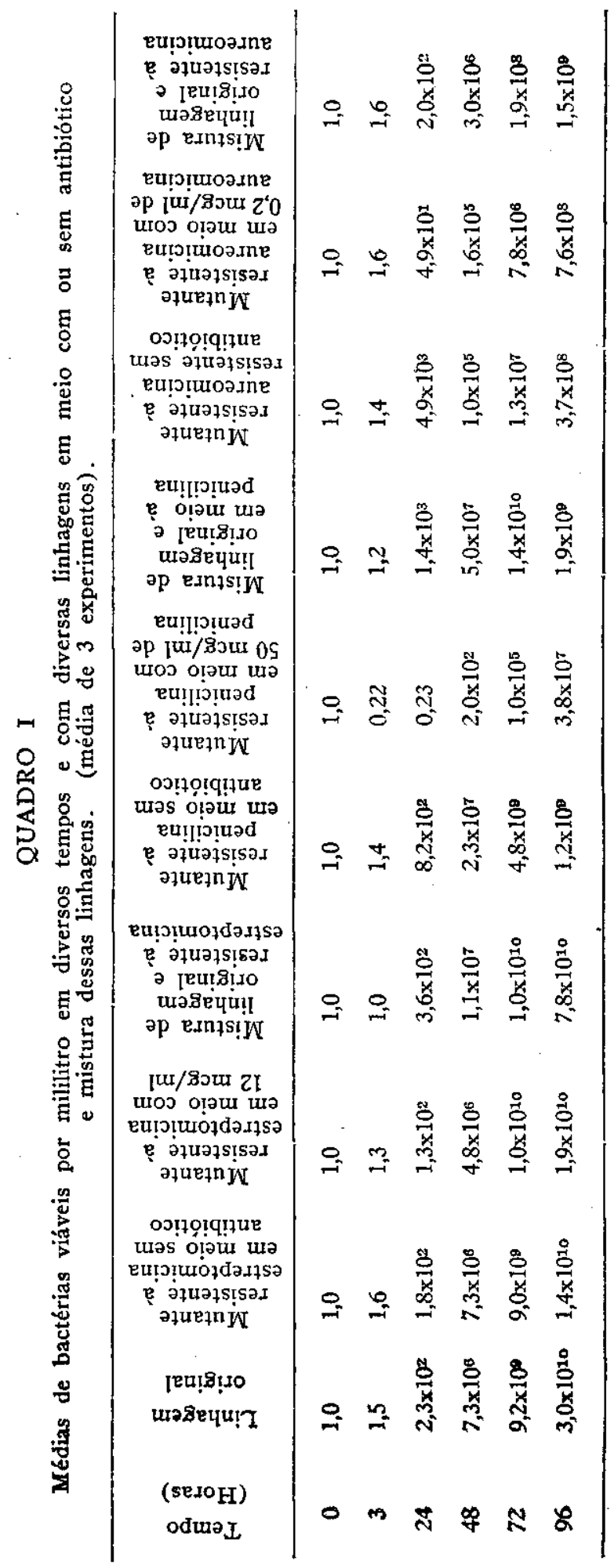




\section{QUADRO II}

Número de gerações e tempo de geração para as diferentes culturas ensaiadas

\begin{tabular}{|c|c|c|}
\hline CULTURAS & $\begin{array}{l}\text { N.o de gerações } \\
\text { (entre } 24 \text { e } \\
48 \text { hs.) }\end{array}$ & $\begin{array}{l}\text { Tempo de } \\
\text { geraçãao } \\
\text { (min.) }\end{array}$ \\
\hline Linhagem original & 14,95 & 96,3 \\
\hline Mutante resistente à estreptomicina & 15,31 & 94,1 \\
\hline $\begin{array}{l}\text { Mutante resistente à estreptomicina } \\
\text { em meio com estreptomicina }\end{array}$ & 15,17 & 94,9 \\
\hline $\begin{array}{l}\text { Mistura sensivel t+ } \\
\text { resistente à estreptomicina }\end{array}$ & 14,90 & 96,6 \\
\hline Mutante resistente à penicilina & 14,77 & 97,5 \\
\hline $\begin{array}{l}\text { Mutante resistente à penicilina } \\
\text { em meio com penicilina }\end{array}$ & 9,76 & 147,5 \\
\hline $\begin{array}{l}\text { Mistura sensivel † } \\
\text { resistente à penicilina }\end{array}$ & 15,13 & 95,2 \\
\hline Mutante resistente à aureomicina & 10,99 & 131,0 \\
\hline $\begin{array}{l}\text { Mutante resistente à aureomicina } \\
\text { em meio com aureomicina }\end{array}$ & 11,12 & 129,5 \\
\hline $\begin{array}{l}\text { Mistura sensível -十 } \\
\text { resistente à aureomicina }\end{array}$ & 13,87 & 103,8 \\
\hline
\end{tabular}


QUADRO III

Mutante resistente à estreptomicina + linhagem original.

\begin{tabular}{|c|c|c|c|}
\hline $\begin{array}{l}\text { Tempo } \\
\text { (horas) }\end{array}$ & $\begin{array}{c}\text { N.o de bactérias } \\
\text { ensaiadas }\end{array}$ & $\begin{array}{l}\text { N.o de bactérias } \\
\text { resistentes }\end{array}$ & $\begin{array}{l}\% \text { de } \\
\text { resistentes }\end{array}$ \\
\hline \multicolumn{4}{|c|}{ 1.0 Experimento } \\
\hline $\begin{array}{r}0 \\
3 \\
24 \\
72\end{array}$ & $\begin{array}{r}1050 \\
1000 \\
7000 \\
327\end{array}$ & $\begin{array}{r}87 \\
90 \\
600 \\
20\end{array}$ & $\begin{array}{l}8,3 \\
9,0 \\
8.6 \\
6,1\end{array}$ \\
\hline \multicolumn{4}{|c|}{$\mathrm{X} 2=5,06$ n. s. $\mathrm{p}=10-20 \%$} \\
\hline \multicolumn{4}{|c|}{ 2.0 Experimento } \\
\hline $\begin{array}{r}0 \\
3 \\
24 \\
48 \\
72\end{array}$ & $\begin{array}{r}953 \\
337 \\
421 \\
87 \\
412\end{array}$ & $\begin{array}{r}171 \\
44 \\
72 \\
10 \\
54\end{array}$ & $\begin{array}{l}17,4 \\
13,0 \\
17,1 \\
11,5 \\
13,1\end{array}$ \\
\hline \multicolumn{4}{|c|}{$\mathrm{X} 2=7,88$ n. s. $\mathrm{p}=5-10 \%$} \\
\hline \multicolumn{4}{|c|}{ 3.0 Experimento } \\
\hline $\begin{array}{r}0 \\
3 \\
48 \\
72\end{array}$ & $\begin{array}{l}477 \\
714 \\
525 \\
110\end{array}$ & $\begin{array}{r}417 \\
614 \\
454 \\
93\end{array}$ & $\begin{array}{l}87,4 \\
86,0 \\
86,5 \\
84,5\end{array}$ \\
\hline & $\mathrm{X} 2=3,41 \mathrm{n}$ & $p=30-40 \%$ & \\
\hline
\end{tabular}


QUADRO IV

Mutante tesistente à penicilina + linhagem original.

\begin{tabular}{|c|c|c|c|}
\hline $\begin{array}{l}\text { Tempo } \\
\text { (horas) }\end{array}$ & $\begin{array}{c}\text { No de bactérias } \\
\text { ensaiadas }\end{array}$ & $\begin{array}{l}\text { N.o de bactérias } \\
\text { resistentes }\end{array}$ & $\begin{array}{l}\% \text { de } \\
\text { resistentes }\end{array}$ \\
\hline \multicolumn{4}{|c|}{ 1.0 Experimento } \\
\hline $\begin{array}{r}0 \\
3 \\
24 \\
48 \\
72\end{array}$ & $\begin{array}{r}113 \\
740 \\
445 \\
32 \\
65\end{array}$ & $\begin{array}{r}70 \\
460 \\
300 \\
21 \\
46\end{array}$ & $\begin{array}{l}61,9 \\
62,2 \\
67,4 \\
65,6 \\
70,8\end{array}$ \\
\hline \multicolumn{4}{|c|}{$\mathrm{x} 2=5,32$ n. s. $\mathrm{p}=20-30 \%$} \\
\hline \multicolumn{4}{|c|}{ 2.0 Experimento } \\
\hline $\begin{array}{r}0 \\
3 \\
24 \\
48\end{array}$ & $\begin{array}{r}173 \\
38 \\
106 \\
40\end{array}$ & $\begin{array}{l}77 \\
13 \\
39 \\
16\end{array}$ & $\begin{array}{l}44,5 \\
34,2 \\
36,8 \\
40,0\end{array}$ \\
\hline \multicolumn{4}{|c|}{$\mathrm{X} 2=2,46 \mathrm{n} . \mathrm{s}, \mathrm{p}=30-50 \%$} \\
\hline \multicolumn{4}{|c|}{ 3." Experiment" } \\
\hline $\begin{array}{r}0 \\
3 \\
24 \\
48 \\
72 \\
96\end{array}$ & $\begin{array}{r}100 \\
45 \\
31 \\
140 \\
215 \\
231\end{array}$ & $\begin{array}{r}90 \\
39 \\
27 \\
120 \\
186 \\
189\end{array}$ & $\begin{array}{l}90,0 \\
86,6 \\
87,1 \\
85,7 \\
86,5 \\
81,8\end{array}$ \\
\hline
\end{tabular}




\section{QUADRO $V$}

Mutante resistente à aureomicina + linhagem original.

\begin{tabular}{|c|c|c|c|}
\hline $\begin{array}{l}\text { Tempo } \\
\text { (horas) }\end{array}$ & $\begin{array}{c}\text { N.o de bactérias } \\
\text { ensaiadas }\end{array}$ & $\begin{array}{l}\text { N.o de bactérias } \\
\text { resistentes }\end{array}$ & $\begin{array}{l}\% \text { de } \\
\text { resistentes }\end{array}$ \\
\hline \multicolumn{4}{|c|}{ 1.0 Experimento } \\
\hline $\begin{array}{r}0 \\
24 \\
48 \\
72 \\
96\end{array}$ & $\begin{array}{r}50 \\
90 \\
412 \\
200 \\
55\end{array}$ & $\begin{array}{r}40 \\
70 \\
314 \\
160 \\
44\end{array}$ & $\begin{array}{l}80,0 \\
77,7 \\
76,2 \\
80,0 \\
80 ; 0\end{array}$ \\
\hline \multicolumn{4}{|c|}{$\mathrm{X} 2=1,99$ n. s. $\mathrm{p}=70-80 \%$} \\
\hline \multicolumn{4}{|c|}{ 2.0 Experimento } \\
\hline $\begin{array}{r}0 \\
3 \\
24 \\
48 \\
72\end{array}$ & $\begin{array}{r}33 \\
79 \\
130 \\
229 \\
70\end{array}$ & $\begin{array}{l}16 \\
35 \\
28 \\
63 \\
10\end{array}$ & $\begin{array}{l}48,5 \\
44,3 \\
21,5 \\
27,5 \\
14,3\end{array}$ \\
\hline \multicolumn{4}{|c|}{$X 2=26,37 * * * p=0.1$} \\
\hline \multicolumn{4}{|c|}{$3 . \%$ Experimento } \\
\hline $\begin{array}{r}0 \\
3 \\
24 \\
48 \\
72\end{array}$ & $\begin{array}{r}17 \\
100 \\
420 \\
19 \\
31\end{array}$ & $\begin{array}{r}6 \\
20 \\
30 \\
\mathbf{3} \\
\mathbf{3}\end{array}$ & $\begin{array}{r}35,2 \\
20,0 \\
7,1 \\
15,8 \\
9,7\end{array}$ \\
\hline & $\mathrm{X} 2=25,7$ & $* * p=0,1$ & \\
\hline
\end{tabular}


